\title{
Deep Ecological Perspective on the Development of China's City Marathon Events
}

\author{
Fan Zhang, 2 \\ ${ }^{1}$ Department of Police Skills and Tactics \\ Nanjing Forest Police College \\ ${ }^{2}$ Sports Science Postdoctoral Programme \\ Nanjing Normal University \\ Nanjing 210023, China \\ zhangfan@nfpc.edu.cn
}

\begin{abstract}
In combination with the basic theory of deep ecology, the development of city marathon events in China is studied in this paper by literature and other research methods. The existing problems in development are as follows: interestscentered and events-centered, lack of ecological concept; focusing on form but ignoring the project characteristics, with incomplete ecological concept. After discussion, put forward the viewpoint: viewing this issue in the holistic way of deep ecology; embodying the basic spirit of deep ecology of inter-growth and symbios is in practice process; reflecting balanced and harmonious ecological wisdom in process of self-realization; dealing with the relationship be tween marathon and related issues on the criterion of equality.
\end{abstract}

Keywords-sports management; event management; city marathon; deep ecology.

\section{INTRODUCTION}

In recent years, China's marathon races have been vigorously implemented, with 306 registered events, 116 events and 231,713 participants in 2016 [1]. However, at the end of 2014, the official website of Chinese Athletic Association showed that the national calendar of marathons and related registered sports had only 39 events [2]. More and more cities and regions are keen to hold marathons, and a complete marathon industry chain has formed. There are two reasons for the national marathon heat: on the one hand, marathon event is not as technical as other track and field events, ordinary people are more receptive; on the other hand, influenced by national policies, marathon events may bring economic benefits to the host city and enhance visibility. How to avoid violating ecological concepts and the nature of marathons while rapidly developing marathons is the focus of this study.

During the events, a large number of people will gather in a city in a short time, it is a concussion on the city and has a certain impact on the urban ecosystem. What are the effects of this social behavior on the whole city? Is it in line with the concept of ecological civilization? Can the rapidly developed

This research was financially supported in part by the Project of China Postdoctoral Science Foundation under Grant 2017M611849, in part by the Project of the Fundamental Research Funds for the Central Universities under Grant LGZD201805, in part by the 13th Five-Year plan project of Jiangsu Education Science under Grant C-c/2018/01/11, in part by Jiangsu Qing Lan Project under Grant 2017, and in part by Pre-research project of Nanjing Forest police College under Grant LGY201603, and in part by Nanjing Forest police College Teaching Reform Project under Grant ZD18104. city marathon events and environment be sustainable? How is the relationship between city marathon with city? Analyzing the above problems with the deep ecology theory and putting forward the practical value of city marathon development are helpful to further enrich the research of deep ecology and marathon, provide theoretical reference for the development of other sports, and have certain practical significance for the overall development of current city marathon events as we'll as the coordinated development of events and city.

\section{PROBLEMS IN THE DEVELOPMENT OF CITY MARATHON EVENTS}

\section{A. Interests-centered and events-centered, lack of ecological concept}

Most of the operation of domestic marathon events is attended by some companies or responsible for specific work. Some companies do not fully consider the long-term development or follow the law of marathon development; pursuit of economic interests has become their primary goal. Essentially, hosting the city marathon has violated deep ecology's requirements of harmonious, orderly and benign development. Deep ecology holds that, based on ecocentrism, mankind must establish a long-term, dynamic, holistic, interrelated and interdependent relationship with nature. Therefore, the organizers and managers should consider from a long-term perspective to view the impact of marathon on city and human health and its role in national fitness rather than violate the law of marathon development because of immediate interests.

On scale, it pursues the large number of people without limit, it seems that more people indicate more successful marathon. For example, a city marathon, with a total of 100,000 participants in 2016, has paid a huge sum of money to invite foreign athletes (mostly African athletes) to participate in competitions in China in pursuit of so-called "internationalization". Someone specializes in this "black business". Marathon has become a money-making tool, this ancient sport has lost its sanctity. In terms of bonuses, it is set higher and higher; and the bonus level has become an important indicator to attract high-level athletes. In order to expand influence, the organizers expand their influence by modern media in many channels and aspects. When choosing 
the track, the organizers usually choose the busy area that reflects the urban characteristics or is representative. Traffic control is also carried out on the event day. To some extent, it restricts the travel freedom of local residents, which violates the requirement of harmonious coexistence with city. In the view of organizers, all available means can be used as long as the event can be made bigger, stronger and more influential. Such a practice centered on event and lacking ecological concepts violates the nature of marathon events development.

\section{B. Focusing on form but ignoring the project characteristics, with incomplete ecological concept}

Majority of marathons are attended by ordinary people, there are relatively small number of professional athletes. Some contestants violate the original intention of holding marathons. Marathon is only one of many track \& field events; because of relatively low entry threshold, non-professional personnel can also participate. Quite a few contestants just want to follow the fashion and do not really like this project. There are people with varying degrees of injury in every marathon: slight as muscle injury and heavy as sudden death. To respect you and ensure health is the basic principle of dealing with the relationship between mankind and oneself in ecological sports and is also the basic ethical base line.

Some competitions are unreasonably organized, there are false in score, and competitions are degraded. Some cities hold many kinds of marathons all year round, e.g. a city held a total of 31 marathon events in 2016. In pursuit of quantity, it should consider how to control the ecological balance among different marathons and how to deal with the ecological balance of participants participating in different marathons in the same city.

One highest principle of deep ecology is self-actualization. For ordinary people, taking part in a marathon is a realization of self-worth and an opportunity to fully display potential. However, they often pay attention to external form, do not grasp the essence, lack comprehensive understandings and do not achieve the true meaning of self-actualization, which will cause physical and psychological harm instead.

\section{PRACTICAL VALUE OF DEEP ECOLOGY TO CITY MARATHON}

The relationship between sports and urban development is not only manifested in the aspects of capital construction and urban appearance transformation, but also widely and deeply printed in basic quality and spirit of residents. [6]Sports can promote urban development and improve the overall quality of citizens within a reasonable range, e.g. Beijing Olympic Games has improved the overall appearance of city and overall quality of citizens. "Human - sports - city" has formed a good cyclic ecosystem, macroscopically, it has ecological integrity; microcosmically, both parties are correlated and interacted. The theory of deep ecology can be utilized to form the harmonious relationship of symbiosis and intergrowth between participants and city marathon events, and then return the sport essence of marathon and return the pure motivation of participants in exercise.

\section{A. Integrity: the ecological horizon of marathon development}

All kinds of marathon races in China can be said as a large system in which all events are interrelated, mutually influenced and restricted. This requires management to co-ordinate all marathon events, avoid man-made vicious competition and the waste of financial, material and human resources. From the perspective of holism, it is necessary to analyze marathon events as an organic whole, focus on the study of elements that affect the whole management process, and extract the meaning of "holism" from these individual elements, i.e. answer that what position the element is in the "whole" management process so as to accurately predict the general trend of development. City planning office should consider the selection of marathon track and cultural display, etc. Sports vendors and manufacturers should also consider the overall coordinated development of various apparel equipment and marathon races, and then view the key links in marathon industry chain with a holistic perspective.

On the other hand, the whole is made up of all internal parts; and the causality should be analyzed [3]. Some cities have many marathon events a year e.g. Beijing and Shanghai. It should deal with the deep ecological relationship among marathon races at different times, the deep ecological relationship between contestants and natural environment, as well as contestants and society, and the deep ecological relationship among contestants, as well as contestants and themselves. The deep ecological relationship is both in the horizontal and vertical correlation, which is also in the dual frame of space-opening and historical continuity. Because the integrity has the wholeness of method, logic, and the unity of internal integrity with external integrity. Deep ecology advocates that man and natural environment, man and social system, man and the whole biological chain and even the whole universe are an organic "ecosystem", and that the components of this system are "interdependent". Therefore, the development of relations between marathon and cities should be viewed from a holistic perspective.

\section{B. Intergrowth and symbiosis: the ecological spirit of marathon development}

Everything has direct or indirect relevance, which also exists between marathons and cities, societies and contestants. Their harmonious coexistence, mutual promotion and improvement are in line with the spirit of deep ecology. Only the related promotion between marathon and cities can make both sides develop better. Cities provide marathon with places, marathons provide opportunities, ideas and modes of development for cities. In this issue, both organizers and participants should pay attention to the issue of "human". When organizing the marathon event, the organizers should first possess correct guiding ideology that is in line with the spirit and concept of deep ecology; they should also adhere to win-win concept of intergrowth and symbiosis, exclude some non-ecological ideas that people can conquer nature and technology is supreme. Deep ecology advocates taking the middle road and tends to humanized and environmentallyfriendly technologies rather than pursue the complexity of science and technology. 
Organizers should not blindly pursue the increasing number of participants, think that "the more the better", they should consider the city capacity, the bearing capacity of surrounding environment, and city's accommodation and transportation conditions. It is worthwhile for us to draw lessons from that Boston marathon race flexibly sets the entry threshold. Man can only produce life, create matter and promote the progress of civilization within the permissible limits of the whole ecosystem, i.e. man must breathe and share the fate with the universe and life. This is also in line with the ideological foundation of deep ecology.

\section{Balance and harmony: the ecological wisdom of marathon development}

Ecological wisdom is a philosophy to study ecological balance and ecological harmony [4]. However, this "balance" and "harmony" has not been well interpreted or even destroyed in the city marathon project. In terms of quantity, it is difficult to balance and coordinate the relationship between marathon project and other track \& field events. Some cities have over 100,000 racers; there even appear marathon number-hawkers. In pursuit of so-called scale, the phenomenon that runs counter to harmony occurs. Ecological balance is an important aspect of ecological wisdom; once destroyed, the entire ecosystem will be affected, which is the so-called "domino". In this ecosystem, various parts should be in harmonious coexistence; only by this, ecological balance can be maintained. Harmony and balance complement and influence each other. In the development course of marathon project, the organizers crave "big" and "many", which invisibly creates disharmony, and then the balance is destroyed.

When organizing city marathon events, it should do best to make people, society and environment coexist in harmony according to city's characteristics, economic development and social development so that contestants can meet the expected needs for physical fitness, the competition can form a virtuous circle, the host city can get proper development and achieve win-win results in all aspects.

\section{Equality: ecological criterion for the development of marathon}

Equality refers to the "ecocentric equality" of deep ecology, which is one of the highest criteria and the ideological basis of deep ecology. This equality principle is the process of cognitive depth and initiative enlargement, and its foundation is the concept of life equality. It not only refers to human beings, human beings are only a small aspect of this equality. All life is equal; and the so-called distinction between higher and lower has merely the meaning of epistemology. That means that human beings can not acquire the privileges and dominating abilities of other categories.

The ideological foundation of deep ecology has a logical premise that all beings in the biosphere have inherent and intrinsic values $[5,6]$. According to the theory of deep ecology, this equality should also be reflected in marathon, but the fact is not the case. As the management organization of marathon, marathon races are rated in different grades according to the relevant indicators and requirements. The original intention of managers may be good; it urges the marathon organizers to be more serious and speed up the development of project through the evaluation. But at the same time, it destroys the regularity of development of project itself, forces some competition organizations to stress evaluation index and related requirements in order to improve the event level. It violates the ecological equality of deep ecology theory. In order to attract more participants [7], different events compete with each other in terms of bonus so as to attract important players. Some competitors even cause personnel fraud and performance fraud only for good results. For other participants, this fraud seriously destroys the fairness principle. The development of Marathon events can only be better promoted by obeying ecological criteria so as to promote healthy development. Equality does not mean that the project does not develop, nor that there is no competition mechanism, but to choose an intermediate path in which everything can develop equally: it does not violate the ecological norms, but also can promote its competitive development.

\section{CONCLUSION}

There are also many non-ecological problems in the rapid development of city marathon events. Project managers should follow the law of project itself, promote and develop marathon more rationally, arrange the national marathon more harmoniously with the holistic approach of deep ecology, achieve mutual benefits between city marathon and surrounding environment, society and other aspects with the win-win concept of deep ecology and idea of symbiosis and intergrowth. At the same time of selfrealization, they should deeply understand the idea of balance and harmony so that "ecological wisdom" can run through the whole marathon practice process; in addition, they should treat the relationship between marathon and environment with an equal perspective, and take this as a criterion to promote the comprehensive and coordinated development of projects.

\section{ACKNOWLEDGMENT}

I want to take this chance to thanks to Postdoctoral tutor---Wang Zhu-ying, a full professor of Nanjing Normal University. In the process of composing this paper, she gives me many academic and constructive advices, and helps me to correct my paper. Except these, she also gave me the opportunity to do my teaching practice. At the same time, I would like to appreciate my doctoral adviser, who gives me useful knowledge and information in this paper. He is Wang Chang-sheng. At last, I am very grateful of my dear friends, Yang Hai-cheng, Zhang Hui, who offered me the confidence and discuss with me about my paper. Of course, I do need to thanks my tennis friend, Jiang Qin-hua, Zhou Ai-ming, Shi Xiang-qun, et al, my mother, He Zu-ying, my father, Zhang Ben-yong, because of their warm care I can grow up well.

\section{REFERENCES}

[1] HU Ying, LI Cui-xia, “Identification and Business Card:a Sociological Study of the Urban Marathon in China,” Journal of Xinzhou Teachers University, vol. 32, pp. 74-77, May 2016. (In Chinese)

[2] NA Na, "Reflections on the Deep Ecology of Urban Planning Based on Deep,” Journal of yunnan rtv university, vol. 11, pp. 80-83, March 2009. (In Chinese) 
[3] Yang Peifeng and Cai Yunnan, “The Research on Urban Space Development Based on the Natural Ecological Vision:Case of Chengdu City,” Chinese landscape architecture, vol. 20, pp. 48-45, July 2004. (In Chinese)

[4] LU Tianfeng, WANG Yue, "Motivation of Urban Middle Class People's Passion for Marathon Seen from Perspective of Cultural Identity and Problems,” Journal of Wuhan Institute of Physical Education, vol. 52, pp. 11-16, April 2018. (In Chinese)
[5] Wang Guangan, "Analysis on Domestic Marathon Hot Based on Sociological Perspective,” Bulletin of Sport Science \& Technology, vol. 25, pp. 114-145, July 2017. (In Chinese)

[6] JIA Xue-jun, "A Systematic Study and the Evaluation of Deep Ecology,” Journal of gansu lianhe UNIVERSITY(SOCIAL SCIENCE EDITION), vol. 23, pp. 5-9, June 2007. (In Chinese)

[7] XUE Yong-min, WANG JI-chuang, "Deep Study on the Environmental Ethics --The Summary of Domestic Research on Deep Ecology in Recent Years,” Journal of jinzhong university, vol. 26, pp. 43-46, September 2009. (In Chinese) 